\title{
Lack of a relationship between serum ferritin levels and coronary atherosclerosis evaluated by coronary arteriography
}

\author{
W.C. Manfroi ${ }^{1}$, A.J. Zago ${ }^{1}$, \\ R. Cruz ${ }^{1}$, J. Oliveira ${ }^{1}$, \\ L.S. Kirschnick ${ }^{1}$, K. O rdovás ${ }^{1}$, \\ R.H. Candiago ${ }^{1}$, J. Souza ${ }^{1}$, \\ L.W. Ribeiro ${ }^{1}$, C. Leitão ${ }^{1}$ \\ and M.L. Brizolara²
}

\author{
${ }^{1}$ Serviço de Cardiologia and 2 Unidade de Bioquímica, \\ Hospital de Clínicas de Porto Alegre, Faculdade de Medicina, \\ Universidade Federal do Rio Grande do Sul, Porto Alegre, RS, Brasil
}

\section{Correspondence \\ W.C. Manfroi \\ Serviço de Cardiologia \\ Hospital de Clínicas de \\ Porto Alegre \\ Rua Ramiro Barcelos, 2350 \\ 90035-003 Porto Alegre, RS \\ Brasil \\ Fax: + 55-51-331-8823 \\ E-mail: manfroi@orion.ufrgs.br \\ Research supported by CNPq and FAPERGS.}

Received August 4, 1997

Accepted December 10, 1998

\begin{abstract}
Many clinical and epidemiological studies have demonstrated the relationship between serum ferritin and ischemic heart disease. In the present study we evaluated the relationship between coronary heart disease (CHD) and serum ferritin levels in patients submitted to coronary arteriography. We evaluated 307 patients (210 (68.7\%) males; median age: 60 years) who were submitted to coronary angiography, measurement of serum ferritin and identification of clinical events of ischemic heart disease. Serum ferritin is reported as quartiles. Ninety-six patients (31.27\%) had normal coronary angiography (group 1) and 211 (68.73\%) had coronary heart disease (group 2). Of the patients with CHD, 61 (28.9\%) had serum ferritin levels higher than $194 \mathrm{ng} / \mathrm{ml}$ (4th quartile), as opposed to only 14 (14.58\%) of those without $\mathrm{CHD}(\mathrm{P}=0.0067)$. In the 2 nd quartile, 39 patients $(18.48 \%)$ had CHD, while 35 patients $(36.46 \%)$ had normal coronary arteries $(\mathrm{P}$ $=0.00064)$. Multivariate analysis of the data showed that the difference between groups was not statistically significant $(\mathrm{P}=0.33)$. We conclude that there is no independent relationship between coronary heart disease and increased levels of serum ferritin.
\end{abstract}

\section{Introduction}

Most deaths in the United States of America are due to ischemic heart disease (IHD) and several risk factors are known to be related to this condition (1-3). Among these factors, it has been demonstrated that total cholesterol and its low density lipoprotein (LDL) fraction are main factors in the genesis and development of coronary atheroscle-
Key words - Ferritin

- Coronary heart disease

- Atherosclerosis

- Risk factors

- Coronary arteriography 
the same time, free radicals have an important action on lipid peroxidation, causing a modification of LDL and facilitating LDL deposition, with the consequent formation of atherosclerotic plaque (8-11). It has been further demonstrated that in vivo, at physiological $\mathrm{pH}$, free radicals are produced at low rates through the reaction of HaberWeiss. Nevertheless, the reaction may be accelerated when it is catalyzed by iron, with a greater production of free radicals (12-18). This is one of the explanations for the greater incidence of ischemic events in males compared to females in the premenopausal state, since during this period the concentration of ferritin is three times higher in men than in women (19-29).

The putative role of iron in the development of atherosclerosis is based on clinical and epidemiological studies. However, no investigations correlating serum concentration of ferritin and anatomic diagnosis of coronary atherosclerosis by coronary arteriography are available in the literature. Thus, the objective of the present study was to evaluate the relationship between concentration of serum ferritin and presence of coronary atherosclerosis.

\section{Population and Methods}

In a transversal study we allocated 307 patients of both sexes with a previous diagnosis of IHD and with a formal indication of coronary arteriography from a physician. Before being submitted to hemodynamic studies, the patients signed an informed consent by which they authorized the collection of $10 \mathrm{ml}$ of blood for laboratory tests. Patients were interviewed according to a standard questionnaire about the presence and clinical aspects of the different forms of angina pectoris. Coronary risk factors such as smoking, systemic arterial hypertension (SAH), diabetes mellitus (DM) and obesity were also investigated. Smoking was defined as the use of more than five cigarettes per day, at least for one year during the last five years; SAH and DM were defined as a previous medical diagnosis or the use of diet or tablets for their treatment; obesity was defined as a body mass index (BMI) higher than 27.3 for females and higher than 27.8 for males, as proposed by the National Institutes of Health Consensus Development (30). Normal values of total cholesterol and LDL cholesterol were considered to be less than $200 \mathrm{mg} / \mathrm{dl}$ and $130 \mathrm{mg} / \mathrm{dl}$, respectively.

Coronary arteriography studies were performed according to the technique of Sones (31) or Judkins (32) after a 12-h fast. For statistical analysis of the sample, any coronary stenosis was considered as coronary heart disease (CHD), the major endpoint. Two experienced observers blindly interpreted the angiographic film.

Ferritin, glucose, total cholesterol and LDL cholesterol were measured in the blood sample. Serum ferritin was measured by enzyme immunoassay using a Bayter Stratus apparatus (Miami, FL, USA).

Levels of serum ferritin were analyzed as quartiles and the means were compared. The cut-off points used were as follows: 1 st quartile - serum ferritin under $68 \mathrm{ng} / \mathrm{ml}$; 2nd quartile - serum ferritin from 68 to $103 \mathrm{ng} /$ $\mathrm{ml}$; 3rd quartile - serum ferritin from 103 to $194 \mathrm{ng} / \mathrm{ml}$; 4th quartile - serum ferritin higher than $194 \mathrm{ng} / \mathrm{ml}$.

Statistical analysis was performed using the chi-square test, ANOVA for paired data, Kruskal-Wallis for non-parametric data and logistic regression for multivariate analysis. Statistical significance was considered as $\mathrm{P}<0.05$.

\section{Results}

Of the 307 patients studied, 96 (31.27\%) had normal coronary arteries (group 1) and $211(68.73 \%$ ) had CHD (group 2).

Sample characteristics are listed in Table 1. Risk factors for coronary heart disease were compared between the group of pa- 
tients with CHD and those without CHD. A statistically significant difference was found between groups when considering age, sex, smoking, obesity, serum total cholesterol and serum LDL cholesterol by univariate analysis. When these variables were included in a logistic regression model, obesity and total serum cholesterol were not statistically significant.

Comparison of the serum ferritin quartiles between groups showed that of the patients without CHD 14 (14.58\%) were in the 4th quartile, as opposed to $61(28.9 \%)$ patients with $\mathrm{CHD}(\mathrm{P}=0.0067)$ (Figure 1). In the 2nd quartile, 39 patients $(36.46 \%)$ had CHD, while 35 patients $(18.48 \%)$ had normal coronary arteries $(\mathrm{P}=0.00064)$. However, when this relationship was controlled for possible confounding factors such as age, sex, race, smoking, obesity, DM, SAH, total serum cholesterol and serum LDL cholesterol by multivariate analysis, no difference was observed $(\mathrm{P}=0.33)$ (Figure 1).

\section{Discussion}

Based on results of experiments with animals, the hypothesis that high concentrations of iron in the organism are associated with accelerated free radical reaction and with increased lipid peroxidation seems to be plausible. More specifically, Balla and colleagues (33) demonstrated that the combination of physiological concentrations of hydrogen peroxide and the heme component of hemoglobin induces a rapid peroxidation of LDL in vitro, liberating free iron from this reaction. It has also been demonstrated that liberation of iron by ferritin stimulates the formation of hydroxyl radicals through superoxide radicals and hydrogen peroxide $(34,35)$.

Sullivan $(16,19,36)$ proposed a possible relationship between iron concentration and greater incidence of CHD in men and postmenopausal women. This hypothesis was based on the high incidence of CHD in patients with hereditary diseases of iron stor- age such as hemochromatosis, as well as the simultaneous increase of cardiovascular risk and serum iron in women after menopause and in old men. Nevertheless, Aronow (37) found no relationship between serum ferritin and CHD in men and women over 62 years.

The objective of the present study was to identify a possible association between serum ferritin concentration and coronary heart disease as evaluated by coronary arteriography. The choice of serum ferritin levels to evaluate iron concentration in the organism was based on previous studies which demonstrated that this is the best method to evaluate the actual condition of iron in the blood (38-40).

Table 1 - Sample characteristics.

SAH, Systemic arterial hypertension; DM, diabetes mellitus; LDL, low density lipoprotein

\begin{tabular}{lccc}
\hline & Coronary heart disease & Control patients & $P$ \\
\hline Age (mean \pm SD, years) & $61.6 \pm 10.6$ & $56.7 \pm 11.4$ & 0.0003 \\
Race (white, \%) & 90 & 85.4 & 0.3 \\
Sex (male, \%) & 68.7 & 43.7 & 0.00005 \\
Smokers (\%) & 33.7 & 15.6 & 0.0018 \\
SAH (\%) & 52.1 & 54.2 & 0.83 \\
DM (\%) & 20.4 & 14.6 & 0.29 \\
Serum cholesterol & $190.9 \pm 43$ & $176.9 \pm 39.1$ & 0.007 \\
(mean \pm SD, mg/dl) & & & \\
Serum LDL cholesterol & $122.6 \pm 37.9$ & $119.3 \pm 82.4$ & 0.018 \\
(mean \pm SD, mg/dl) & & & \\
Obesity (\%) & 13.7 & 26 & 0.013 \\
Stable angina (\%) & 31.2 & 30.6 & 0.92 \\
Unstable angina (\%) & 59.4 & 60 & 0.93 \\
Atypical angina (\%) & 9.4 & 9.4 & 1
\end{tabular}

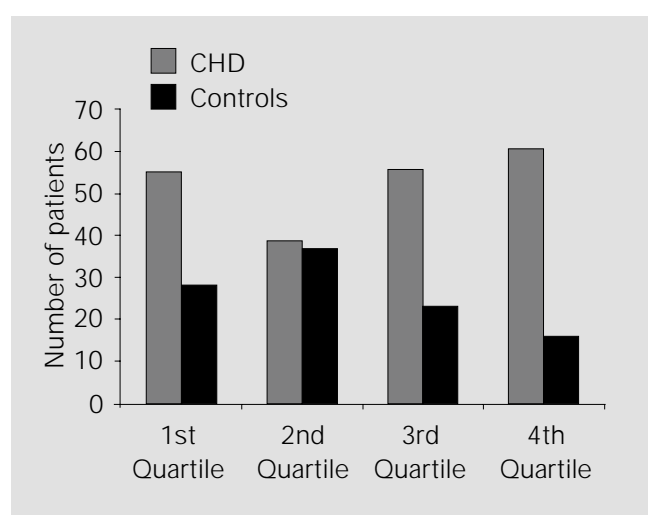

Figure 1 - Patient distribution according to ferritin quartiles. $\mathrm{CHD}=$ Coronary heart disease. 
In this sample, main risk factors for CHD indeed proved to be higher in the group of patients with this condition. By analyzing our data about the main endpoint, we conclude that there is no independent relationship between serum ferritin and CHD. In spite of the evidence in literature for a direct role of iron in the pathogenesis of atherosclerosis, serum ferritin levels do not reflect this process. Probably there are local factors that determine the iron activity, independ- ently of the systemic concentration of iron. Studies focusing on this subject should be performed to elucidate this important question.

\section{Acknowledgments}

We specially thank the nursing staff of the Unidade de Hemodinâmica of Hospital de Clínicas de Porto Alegre.

\section{References}

1. Abbot RD \& McGee D (1987). The probability of developing certain cardiovascular diseases in eight years at specified values of some characteristics. In: Kannel WB, Wolf PA \& Garrison RJ (Editors), The Framingham Study: An Epidemiological Investigation of Cardiovascular Disease. Section 37. Publication NIH 87-2284. US Department of Health Education, and Welfare, Washington, DC.

2. Simons LA (1986). Interrelations of lipids and lipoproteins with coronary artery disease mortality in 19 countries. American J ournal of Cardiology, 57: 5G-10G.

3. Castelli WP, Garrison RJ \& Wilson PWF (1986). Incidence of coronary heart disease and lipoprotein cholesterol levels: The Framingham Study. J ournal of the American Medical Association, 256: 28352838.

4. The Canadian Consensus Conference on Cholesterol (1988). Final report. Canadian Medical Association J ournal, 139 (Suppl 1): 1-8.

5. Watts GF, Mandalia S, Brunt J N, Slavin BM, Coltart DJ \& Lewis B (1993). Independent associations between plasma lipoprotein subfraction levels and the course of coronary artery disease in the St. Thomas Atherosclerosis Regression Study. Metabolism, 42: 1461-1467.

6. Philips NR, Waters D \& Havel RJ (1993). Plasma lipoprotein and progression of coronary artery disease evaluated by angiography and clinical events. Circulation, 88: 2762-2770.

7. Ross R (1996). The pathogenesis of atherosclerosis - an update. New England J ournal of Medicine, 314: 488-500.

8. Chisolm GM (1991). Cytotoxicity of oxidized lipoproteins. Current Opinion in Lipidology, 2: 311-316.

9. Carpenter KLH, Brabbs CE \& Mitchinson
MJ (1991). Oxygen radicals and atherosclerosis. Klinische Wochenschrift, 69: 1039-1045.

10. Esterbauer G, Wag G \& Puhl H (1993). Lipid peroxidation: its role in atherosclerosis. British Medical Bulletin, 49: 566-576.

11. Steinberg $D$, Parthasarathy $S$, Carew TE, Khoo J C \& Witztum J L (1989). Beyond cholesterol: Modifications of low density lipoprotein that increase its atherogenicity. New England J ournal of Medicine, 320: 915-923.

12. McCord J M (1991). Is iron sufficiency a risk factor in ischemic heart disease? Circulation, 83: 1112-1114.

13. Cross $C E$, Halliwell $B$, Borish ET, Pryor WA, Saul RL, McCord J M \& Harman D (1987). Oxygen radicals and human disease. Annals of Internal Medicine, 107: 526-545.

14. Halliwell B \& Gutteridge J MC (1989). Free Radicals in Biology and Medicine. 2nd edn. Clarendon Press, Oxford.

15. Halliwell B \& Gutteridge J MC (1990). Role of free radicals and catalytic metal ions in human disease: An overview. In: Packer L $\&$ Glazer AN (Editors), Methods in Enzymology. Vol. 186. Academic Press, San Diego, 1-85.

16. Sullivan J L (1989). The iron paradigm of ischemic heart disease. American Heart J ournal, 117: 1177-1188.

17. Aust SD \& Svingen BA (1982). The role of iron in enzymatic lipid peroxidation. In: Pryor WA (Editor), Free Radicals in Biology. Vol. V. Academic Press, New York. 128.

18. Heinecke J W, Rosen H \& Chait A (1984). Iron and copper promote modification of low density lipoprotein by human arterial smooth muscle cells in culture. J ournal of Clinical Investigation, 74: 1890-1894.

19. Sullivan J L (1981). Iron and the sex differ- ence in heart disease risk. Lancet, 1: 12931294.

20. Kannel WB, Hjortland MC, McNamara PM $\&$ Gordon T (1976). Menopause and the risk of cardiovascular disease. The Framingham Study. Annals of Internal Medicine, 85: 447-452.

21. Sullivan J L (1983). The sex difference in ischemic heart disease. Perspectives in Biology and Medicine, 26: 657-671.

22. Colditz GA, Willett WC, Stampfer MJ, Rosner B, Speizer FE \& Hennekens $\mathrm{CH}$ (1987). Menopause and the risk of coronary heart disease in women. New England J ournal of Medicine, 316: 1105-1110.

23. Lauffer RB (1991). Iron stores and the international variation in mortality from coronary artery disease. Medical Hypotheses, 35: 96-102.

24. Cullen KJ , Stenhouse NS \& Waerne KL (1981). Raised hemoglobin and risk of cardiovascular disease. Lancet, 4: 1288-1289.

25. Robinson RW, Higano N \& Cohen WD (1959). Increased incidence of coronary heart disease in women castrated prior to menopause. Archives of Internal Medicine, 104: 908-913.

26. Gordon T, Kannel WB, Hjortland MC \& McNamara PM (1978). Menopause and coronary heart disease: the Framingham Study. Annals of Internal Medicine, 89: 157-161.

27. Salonen JT, Nyyssönen $K$, Korpela $H$, Tuomilehto J, Seppänen R \& Salonen R (1992). High stored iron levels are associated with excess risk of myocardial infarction in eastern Finnish men. Circulation, 86: 803-811.

28. Sempos CT, Looker AC, Gillum RF \& Makuc DM (1994). Body iron stores and the risk of coronary heart disease. New England J ournal of Medicine, 330: 11191124. 
29. Salonen J T, Nyyssönen $\mathrm{K} \&$ Salonen $\mathrm{R}$ (1994). Body iron stores and the risk of coronary heart disease. New England J ournal of Medicine, 331: 1159-1160.

30. National Institutes of Health Consensus Development Conference Statement (1985). National Institutes of Health Consensus Development Panel on the Health Implications of Obesity. Annals of Internal Medicine, 103 (Suppl 2): 1073-1077.

31. Sones FJ \& Sinrey EK (1962). Coronary arteriography. Modern Concepts of Cardiovascular Disease, 31: 735-738.

32. J udkins MF (1967). Selective coronary arteriography: a percutaneous transfemoral technique. Radiology, 89: 815-824.
33. Balla G, J acob HS, Eaton J W, Belcher J D \& Vercellotti GM (1991). Hemin: A possible physiological mediator of low density lipoprotein oxidation and endothelial injury. Arteriosclerosis and Thrombosis, 11: 1700-1711.

34. Carlin G \& Djursater R (1984). Xanthine oxidase induced depolymerization of hyaluronic acid in the presence of ferritin. FEBS Letters, 177: 27-30.

35. Cozzi A, Santambrogio P, Levi S \& Arosio $P$ (1990). Iron detoxifying activity of ferritin: Effects of $H$ and $L$ apoferritins on lipid peroxidation in vitro. FEBS Letters, 277: 119-122.

36. Sullivan JL (1986). Sex, iron, and heart disease. Lancet, 2:1162.

37. Aronow WS (1993). Serum ferritin is not a risk factor for coronary artery disease in men and women aged $>62$ years. American J ournal of Cardiology, 72: 347-348.

38. Willet W (1990). Nutritional Epidemiology. Oxford University Press, New York.

39. Cook J D, Lipschitz DA, Miles LE \& Finch CA (1974). Serum ferritin as a measure of iron stores in normal subjects. American J ournal of Clinical Nutrition, 27: 681-687.

40. Kaltwasser J P \& Werner E (1989). Diagnosis and clinical evaluation of iron overload. Baillieres Clinical Haematology, 2: 363-385. 